\title{
PENGARUH VARIASI BERAT BADAN TERHADAP KENAIKAN TEMPERATUR TUBUH DAN NILAI SPECIFIC ABSORPTION RATE PADA PEMERIKSAAN MRI BRAIN
}

\author{
${ }^{1}$ Dimas Prakoso, ${ }^{2}$ Fatimah, ${ }^{3}$ Bagus Abimanyu, ${ }^{4}$ Dartini \\ 1,2,3,4) Jurusan Teknik Radiodiagnostik dan Radioterapi Poltekkes Kemenkes Semarang \\ Jl. Tirto Agung Pedalangan Banyumanik Semarang \\ e-mail : dimas.kepodang@gmail.com
}

\begin{abstract}
Background : MRI brain is a routine examination, after finished examination will felt warm and sweaty on the back. The heat produced by the SAR effect affected by the body weight examined. This research to determine increasing body temperature and SAR value after MRI brain examination based on different body weight.

Methods :The kind of this research is experiment. Research has been done at thirteen (13) samples with characteristic as follows : consisted of 3 men and 10 women with variation of body weight $45 \mathrm{~kg}$ until $75 \mathrm{~kg}$. Samples had normal body temperature, no abnormalities in the head, and no claustrophobia. Each samples measure body weight and body temperature before MRI examination, then performed examination of MRI brain used brain routine protocol during 19 minutes 49 seconds. After that, measure body temperature again to find the increasing body temperature and saw the SAR value on SAR information. Then analyzed the affection of the variation of body weight and increasing body temperature, and variation of body weight and SAR value. Data were analysed statistically by using Linear Regression test.

Results : The results showed that there were significant affection between variation of body weight and increasing body temperature ( $\mathrm{p}$ value $<0,05$ ) significant with very strong influence $(\mathrm{R}$ Square $=0,889$ ) and negative correlation with equation $y=2,098-0,024 x$. On variation of body weight and SAR value showed that there were significant affection $(\mathrm{p}$ value $<0,05)$ with medium influence $(\mathrm{R}$ Square $=0,596)$ and positive correlation with equation $\mathrm{y}=0,214+0,004 \mathrm{x}$.
\end{abstract}

Conclusion : Based on these results indicate thatmore body weight, increase body temperature will decrease due to the fat in people overweight and more body weight, SAR value will increase according the amount of RF exposure required

Keywords : body weight, temperature, SAR value, MRI brain.

\section{Pendahuluan}

Magnetic Resonance Imaging adalah suatu teknik penggambaran penampang tubuh berdasarkan prinsip resonansi magnetik dari inti atom hidrogen tubuh dan tanpa menggunakan sinar-X. MRI menciptakan gambar yang dapat menunjukkan perbedaan sangat jelas dan lebih sensitif untuk menilai anatomi jaringan lunak dalam tubuh terutama otak, sumsum tulang belakang, dan sumsum saraf dibandingkan dengan pemeriksaan sinar-X biasa maupun CT- Scan. Teknik penggambaran MRI relatif kompleks karena gambaran yang dihasilkan tergantung pada banyak parameter, bila pemilihan parameter tepat maka kualitas gambaran, detail tubuh manusia akan tampak jelas sehingga anatomi dan patologi jaringan 
tubuh dapat dievaluasi secara teliti (Rasad, 2006).

Magnet yang digunakan pada beberapa sistem MRI merupakan magnet dengan tipe superconductor, hal ini berarti jika sekali saja arus listrik dialirkan pada magnet untuk menghasilkan medan magnet maka arus akan mengalir pada coil. Kekuatan medan magnet dinyatakan dengan satuan Tesla, 1 Tesla sama dengan 10.000 Gauss (Hashemi dan Bradley, 2010).

Suatu sistem MRI tidak hanya membutuhkan medan magnet yang kuat tetapi juga harus memberikan suatu sinyal radiofrekuensi (RF) dengan tujuan untuk memperoleh respon dari organ yang diperiksa. Pembangkitan medan RF tersebut dilakukan tidak berdasarkan radiasi ionisasi seperti halnya 
yang terjadi pada sinar- $X$ yang dapat mengubah struktur kimiawi pada zat yang terkena, tetapi ini berdasarkan dengan pembangkitan medan RF yang dapat menimbulkan pemanasan pada jaringan.

Pulsa RF yang diserap oleh tubuh ketika medan elektromagnetik dipancarkan disebut efek Specific Absorption Rate (SAR). Efek SAR didefinisikan sebagai daya yang diserap per masa jaringan dan memiliki satuan watt per kilogram (W/Kg). Efek SAR dapat menyebabkan perubahan temperatur pada jaringan tubuh (Bushong, 2004).

Pada saat proses pencitraan gambar, sebagian besar medan elektromagnetik RF yang ditransmisikan berubah menjadi panas dalam jaringan tubuh sehingga dapat berakibat kerugian (Shellock, 2000).

Peningkatan temperatur tubuh karena pulsa RF dapat membuat pasien merasa tidak nyaman dan memungkinkan terjadinya motions artifact karena pergerakan pasien. Selain itu, pada saat nilai SAR yang meningkat pada pesawat MRI diharapkan dapat segera merubah beberapa parameter akuisisi spesifik seperti Time

Repetition (TR), jumlah irisan, Echo Train

Length (ETL), dan/atau amplitudo pulsa RF seperti mengubah flip angle (FA) (Baker, 2004).

Penurunan nilai SAR yang dapat dilakukan secara manual dengan meningkatkan nilai TR yang mengakibatkan meningkatkan waktu scanning. Selain itu, menggunakan flip angle yang kecil sehingga daya RF yang dibutuhkan lebih rendah mengakibatkan nilai SAR dapat

bekurang (Hancock, 2010).

Nilai SAR telah ditetapkan oleh International Electrotechnical Commission (IEC) dengan batas maksimum untuk tubuh 4 $\mathrm{W} / \mathrm{Kg}$, kepala $3.2 \mathrm{~W} / \mathrm{Kg}$, kepala dan tubuh 20 $\mathrm{W} / \mathrm{Kg}$, dan untuk ektremitas $40 \mathrm{~W} / \mathrm{Kg}$. Nilai SAR dapat dilihat pada monitor pesawat MRI pada SAR information (Homann, 2011).

Temperatur rata-rata tubuh adalah $37^{\circ} \mathrm{C}$ dengan rentang normal $36^{\circ} \mathrm{C}$ hingga $37^{\circ} \mathrm{C}$. Perubahan temperatur tubuh diatur oleh hipotalamus, namun dapat berubah karena pengaruh radiasi, konduksi panas dari kulit ke udara sekitar, maupun evaporasi air (Isnaeni, 2006).
Ambang batas peningkatan suhu tubuh karena efek SAR dalam batas aman hingga kenaikan $2^{\circ} \mathrm{C}$. Kenaikan suhu tubuh ini dipengaruhi oleh berat badan pasien yang diperiksa. Sehingga, sebelum dilakukan pemeriksaan MRI perlu ditimbang berat badan 
terlebih dahulu. Dengan dilakukannya penimbangan berat badan, diharapkan dapat mengetahui nilai SAR sehingga nilai peningkatan suhu tubuh dapat diketahui (Bushong, 2004).

Kenaikan temperatur tubuh tidak meningkat secara signifikan berdasarkan BMI yang meningkat. Kenaikan dikatagorikan kelebihan berat badan tingkat ringan dan kelebihan berat badan tingkat berat

(obesitas) (Depkes, 2002).

Pemeriksaan MRI brain merupakan pemeriksaan yang rutin dan sering dilakukan, pasien banyak yang merasakan pusing setelah dilakukan MRI brain. Selain itu, ketika pesawat MRI sudah melewati batas nilai SAR yang ditetapkan IEC, kita diminta untuk menaikkan nilai TR atau menurunkan flip angle untuk mengurangi paparan RF yang diserap tubuh, namun berakibat pada hasil citra yang tidak sesuai dengan yang diinginkan.

Di Instalasi Radiologi Rumah Sakit Pusat Pertamina, terdapat berbagai macam pemeriksaan MRI. Pemeriksaan MRI brain merupakan pemeriksaan yang sering dilakukan, selama pemeriksaan berlangsung terkadang pasien mengeluhkan waktu pemeriksaan yang lama dan suara yang dihasilkan dari pesawat MRI yang menganggu, selain itu pasien merasakan hangat dan berkeringat pada punggung setelah selesai dilakukan pemeriksaan MRI. Dikarenakan pesawat MRI dapat meningkatkan temperatur tubuh, maka kita diharapkan dapat mengubah beberapa parameter pada pemeriksaaan MRI untuk pasien memiliki kelainan temperatur tubuh yang tinggi.
Jenis penelitian ini adalah penelitian kuantitatif dengan eksperimental. Pengambilan data dilakukan pada tanggal 1 sampai 10 April 2017 di Instalasi Radiologi Rumah Sakit Pusat Pertamina Jakarta. Populasi dan sampel penelitian adalah volunteer atau sukarelawan berjumlah 13 orang dengan variasi berat badan dari $45 \mathrm{~kg}$ hingga $75 \mathrm{~kg}$. Pobandus memiliki temperatur tubuh normal berkisar 36 hingga 37 temperatur

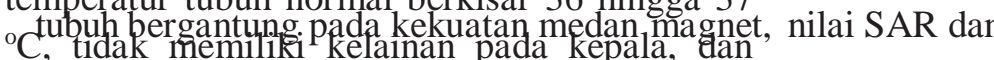
tidak takut dalam ruang sempit (claustrophobia). 
Sebelum melakukan penelitian, dilakukan kalibrasi terhadap alat ukur. Kalibrasi terhadap timbangan digital dilakukan dengan melakukan pengukuran terhadap air dalam plastik, dengan massa jenis air $1 \mathrm{~g} / \mathrm{cm}^{3}$ artinya pengukuran 1 liter air sama dengan $1 \mathrm{~kg}$. Kalibrasi termometer digital dilakukan dengan menggunakan termometer raksa dan membandingkan pengukuran air yang dipanaskan pada rentang 32 hingga $42{ }^{\circ} \mathrm{C}$. Kalibrasi terhadap nilai RF pesawat MRI dengan menggunkan phantom dan memasukkan nilai berat badan $40 \mathrm{~kg}$ dan $80 \mathrm{~kg}$ pada kolom registrasi kemudian lakukan scanning T2 axial TSE, setelah selesai scanning lihat nilai RF pada SAR information bagian time averaged $R F$ power nilai yang ditampilkan harus sama.

Prosedur penelitian dengan melakukan pengukuran berat badan dengan menggunakan timbangan digital dan pengukuran temperatur tubuh sebelum pemeriksaan MRI pada ruang tunggu pemeriksaan MRI. Pengukuran temperatur tubuh dilakukan dengan termometer digital, pengukuran dilakukan pada ketiak dalam keadaan supine diatas transport table. Selanjutnya dari ruang tunggu pemeriksaan MRI berpindah ke ruang pemeriksaan MRI dengan menggunakan transport table dalam keadaan supine untuk dilakukan pemeriksaan MRI brain routine.

Tabel 1. Sequence MRI brain routine

\begin{tabular}{cc}
\hline Sequence & Waktu Scanning \\
\hline Localizer sagital & 14 detik \\
Localizer coronal + axial & 14 detik \\
T2 sagital FLAIR & 3 menit 56 detik \\
T2 axial TSE & 2 menit 30 detik \\
T1 axial SE & 3 menit 42 detik \\
T2 axial FLAIR & 3 menit 20 detik \\
T2 coronal FLAIR & 4 menit 37 detik \\
DWI & 1 menit 16 detik \\
\hline
\end{tabular}

Total waktu scanning 19 menit 49 detik.

Setelah melakukan pemeriksaan MRI brain berpindah ke transport table dengan cara bergeser. Dari ruang pemeriksaan MRI berpindah ke ruang tunggu pemeriksaan MRI untuk dilakukan pengukuran temperatur tubuh setelah pemeriksaan MRI dalam keadaan supine untuk mengetahui nilai kenaikan temperatur tubuh. Pengukuran temperatur tubuh dilakukan pada ruang tunggu pemeriksaan karena tidak dimungkinkan melakukan pengukuran 
temperatur tubuh dalam ruangan MRI. Selain itu, melihat nilai SAR pada SAR information pesawat MRI.

Analisis data dilakukan uji statistik dengan aplikasi SPSS 17. Data tersebut diolah dengan uji regresi linear untuk mengetahui apakah ada pengaruh antara variasi berat badan terhadap kenaikan temperatur tubuh dan antara variasi berat badan terhadap nilai SAR, selain itu dibuat persamaan nilai pengaruh dan dibuat grafik untuk mengetahui kecenderungan.

\section{Hasil dan Pembahasan}

Penelitian ini dilakukan terhadap 13 probandus berjenis kelamin lakilaki 3 orang dan perempuan 10 orang, rentang usia 19 tahun sampai 27 tahun dengan berat $45 \mathrm{~kg}$ sampai $75 \mathrm{~kg}$ yang melakukan pengukuran berat badan, pengukuran temperatur tubuh sebelum dan sesudah dilakukan pemeriksaan MRI. Pemeriksaan MRI menggunakan sequence brain routine.

Tabel 2. Karakteristik probandus

\begin{tabular}{cccc}
\hline Probandus & $\begin{array}{c}\text { Umur / Jenis } \\
\text { Kelamin }\end{array}$ & $\begin{array}{c}\text { Berat } \\
\text { Badan }\end{array}$ & $\begin{array}{c}\text { Temperatur } \\
\text { Tubuh }\end{array}$ \\
\hline 1 & $23 \mathrm{Th} /$ perempuan & $45,6 \mathrm{~kg}$ & $36,3^{\circ} \mathrm{C}$ \\
2 & $20 \mathrm{Th} /$ perempuan & $48,9 \mathrm{~kg}$ & $36,2^{\circ} \mathrm{C}$ \\
3 & $21 \mathrm{Th} /$ perempuan & $51,4 \mathrm{~kg}$ & $36,1^{\circ} \mathrm{C}$ \\
4 & $19 \mathrm{Th} /$ perempuan & $52,1 \mathrm{~kg}$ & $36,2{ }^{\circ} \mathrm{C}$ \\
5 & $19 \mathrm{Th} /$ perempuan & $54,5 \mathrm{~kg}$ & $36,1^{\circ} \mathrm{C}$ \\
6 & $27 \mathrm{Th} /$ perempuan & $55,2 \mathrm{~kg}$ & $36,2{ }^{\circ} \mathrm{C}$ \\
7 & $20 \mathrm{Th} /$ perempuan & $55,7 \mathrm{~kg}$ & $36,0^{\circ} \mathrm{C}$ \\
8 & $19 \mathrm{Th} /$ perempuan & $57,1 \mathrm{~kg}$ & $36,3{ }^{\circ} \mathrm{C}$ \\
9 & $20 \mathrm{Th} /$ perempuan & $60,7 \mathrm{~kg}$ & $36,0^{\circ} \mathrm{C}$
\end{tabular}

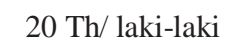

$$
66,4 \mathrm{~kg}
$$$$
36,4{ }^{\circ} \mathrm{C}
$$$$
11
$$$$
21 \mathrm{Th} / \text { laki-laki }
$$$$
73,5 \mathrm{~kg}
$$$$
36,1^{\circ} \mathrm{C}
$$

$21 \mathrm{Th} /$ laki-laki

$74,3 \mathrm{~kg}$

$36,0^{\circ} \mathrm{C}$

13

$20 \mathrm{Th} /$ perempuan

$$
74,5 \mathrm{~kg}
$$

$36,4^{\circ} \mathrm{C}$

Dari tigabelas probandus diperoleh kenaikan temperatur tubuh dari selisih temperatur setelah dilakukan pemeriksaan dengan sebelum dilakukan pemeriksaan MRI. Selain itu didapat nilai SAR dari SAR information monitor pesawat MRI.

1. Pengaruh variasi berat badan terhadap kenakan temperatur tubuh pada pemeriksaan MRI brain

Tabel 3. Pengaruh variasi berat badan terhadap kenaikan temperatur tubuh 


\begin{tabular}{cccc}
\hline $\begin{array}{c}\text { Berat } \\
\text { Badan }\end{array}$ & $\begin{array}{c}\text { Temperatur } \\
\text { Tubuh } \\
\text { Sebelum }\end{array}$ & $\begin{array}{c}\text { Temperatur } \\
\text { Tubuh } \\
\text { Setelah }\end{array}$ & $\begin{array}{c}\text { Kenaikan } \\
\text { Temperatur } \\
\text { Tubuh }\end{array}$ \\
\hline $45,6 \mathrm{~kg}$ & $36,3^{\circ} \mathrm{C}$ & $37,2^{\circ} \mathrm{C}$ & $0.9^{\circ} \mathrm{C}$ \\
$48,9 \mathrm{~kg}$ & $36,2^{\circ} \mathrm{C}$ & $37.3^{\circ} \mathrm{C}$ & $1.1^{\circ} \mathrm{C}$ \\
$51,4 \mathrm{~kg}$ & $36,1^{\circ} \mathrm{C}$ & $37.1^{\circ} \mathrm{C}$ & $1.0^{\circ} \mathrm{C}$ \\
$52,1 \mathrm{~kg}$ & $36,2^{\circ} \mathrm{C}$ & $37.1^{\circ} \mathrm{C}$ & $0.9^{\circ} \mathrm{C}$ \\
$54,5 \mathrm{~kg}$ & $36,1^{\circ} \mathrm{C}$ & $36,9^{\circ} \mathrm{C}$ & $0.8^{\circ} \mathrm{C}$ \\
$55,2 \mathrm{~kg}$ & $36,2^{\circ} \mathrm{C}$ & $36.9^{\circ} \mathrm{C}$ & $0.7{ }^{\circ} \mathrm{C}$ \\
$55,7 \mathrm{~kg}$ & $36,0^{\circ} \mathrm{C}$ & $36.7^{\circ} \mathrm{C}$ & $0.7{ }^{\circ} \mathrm{C}$ \\
$57,1 \mathrm{~kg}$ & $36,3^{\circ} \mathrm{C}$ & $37.1^{\circ} \mathrm{C}$ & $0.8^{\circ} \mathrm{C}$ \\
$60,7 \mathrm{~kg}$ & $36,0^{\circ} \mathrm{C}$ & $36.6^{\circ} \mathrm{C}$ & $0.6{ }^{\circ} \mathrm{C}$
\end{tabular}

temperatur tubuh dapat dilihat dari uji regresi linear pada kolom $R$ Square.

Tabel 5. Hasil uji regresi $R$ Square variasi berat badan terhadap kenaikan temperatur tubuh

\begin{tabular}{ccccc}
\hline Model & $\mathbf{R}$ & $\boldsymbol{R}$ Square & $\begin{array}{c}\text { Adjusted } \\
\text { R Square }\end{array}$ & $\begin{array}{c}\text { Std. Error of } \\
\text { the Estimate }\end{array}$ \\
\hline 1 & 0,942 & 0,887 & 0,887 & 0,0870
\end{tabular}

Untuk menentukan persamaan variasi berat badan terhadap kenaikan temperatur tubuh dapat dilihat dari uji regresi linear pada kolom nilai B.

Tabel 6. Hasil uji regresi nilai B variasi berat badan terhadap kenaikan temperatur tubuh

\begin{tabular}{ccccc}
\hline \multicolumn{5}{c}{ Unstandardized } \\
& & Coefficients & $t$ & Sig. \\
Model & B & Std. Error & & \\
& & & & \\
\hline 1 (Constant) & 2,098 & 0,152 & 13,795 & 0,000 \\
berat & $-0,024$ & 0,003 & $-0,9312$ & 0,000 \\
& & & & \\
\hline
\end{tabular}

2. Pengaruh variasi berat badan terhadap nilai SAR pada pemeriksaan MRI brain

Tabel 7. Pengaruh variasi berat badan terhadap nilai SAR

\begin{tabular}{cc}
\hline $\begin{array}{c}\text { Berat } \\
\text { Badan }\end{array}$ & Nilai SAR \\
\hline $45,6 \mathrm{~kg}$ & $0,4 \mathrm{~W} / \mathrm{Kg}$ \\
$48,9 \mathrm{~kg}$ & $0,4 \mathrm{~W} / \mathrm{Kg}$ \\
$51,4 \mathrm{~kg}$ & $0,4 \mathrm{~W} / \mathrm{Kg}$
\end{tabular}

Untuk melihat hubungan variasi berat badan terhadap
Tabel 4. Hasil uji paired T test pengaruh variasi berat badan terhadap kenaikan temperatur tubuh

\begin{tabular}{llll}
\hline N & Correlation & Sig. \\
\hline
\end{tabular}

Berat \&

Suhu

$13 \quad-0,942 \quad 0,000$


kenaikan temperatur tubuh dapat dilihat dengan grafik dibawah ini.

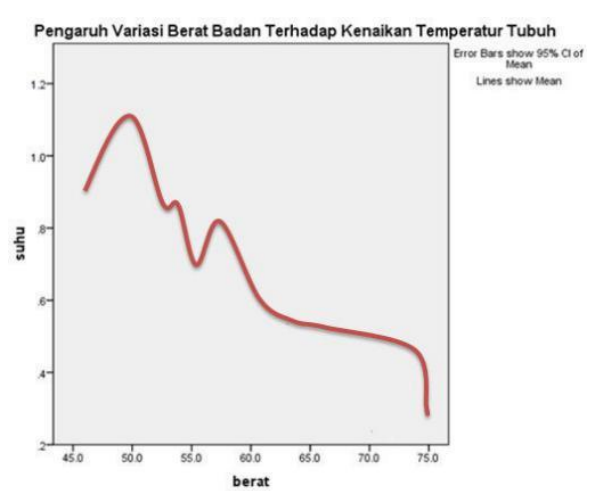

Gambar 1. Grafik pengaruh variasi berat badan terhadap kenaikan temperatur tubuh

Untuk menentukan nilai pengaruh variasi berat badan terhadap kenaikan

$$
\begin{array}{lll}
52,1 \mathrm{~kg} & 0,4 \mathrm{~W} / \mathrm{Kg} \\
54,5 \mathrm{~kg} & 0,4 \mathrm{~W} / \mathrm{Kg} \\
55,2 \mathrm{~kg} & 0,4 \mathrm{~W} / \mathrm{Kg} \\
55,7 \mathrm{~kg} & 0,5 \mathrm{~W} / \mathrm{Kg} \\
57,1 \mathrm{~kg} & 0,5 \mathrm{~W} / \mathrm{Kg} \\
60,7 \mathrm{~kg} & 0,5 \mathrm{~W} / \mathrm{Kg} \\
66,4 \mathrm{~kg} & 0,5 \mathrm{~W} / \mathrm{Kg} \\
73,5 \mathrm{~kg} & 0,5 \mathrm{~W} / \mathrm{Kg} \\
74,3 \mathrm{~kg} & 0,5 \mathrm{~W} / \mathrm{Kg} \\
74,5 \mathrm{~kg} & 0,5 \mathrm{~W} / \mathrm{Kg}
\end{array}
$$

Data yang diperoleh dianalisis dengan menggunakan uji statistik regresi linear untuk mengetahui pengaruh berat badan terhadap nilai SAR

Hasil uji statistik pengaruh variasi berat badan terhadap nilai SAR pada pemeriksaan 
MRI brain menunjukkan adanya pengaruh, dapat dilihat dari hasil statistik $T$ test.

Tabel 8. Hasil uji paired T test pengaruh variasi berat badan terhadap nilai SAR

\begin{tabular}{cccc}
\hline & N & Correlation & Sig. \\
\hline Berat \& SAR & 13 & 0,772 & 0,002
\end{tabular}

Untuk melihat hubungan variasi berat badan terhadap nilai SAR dapat dilihat dengan grafik dibawah ini.



Gambar 2. Grafik pengaruh variasi berat badan terhadap nilai SAR

Untuk menentukan nilai pengaruh variasi berat badan terhadap nilai SAR dapat dilihat dari uji regresi linear pada kolom $R$ Square.

Tabel 9. Hasil uji regresi $R$ Square variasi berat badan terhadap nilai SAR

\begin{tabular}{ccccc}
\hline Model & $\mathbf{R}$ & $\boldsymbol{R}$ Square & $\begin{array}{c}\text { Adjusted } \\
\text { R Square }\end{array}$ & $\begin{array}{c}\text { Std. Error of } \\
\text { the Estimate }\end{array}$ \\
\hline 1 & 0,772 & 0,596 & 0,560 & 0,0344
\end{tabular}

Untuk menentukan persamaan variasi berat badan terhadap nilai SAR dapat dilihat
1. Pengaruh variasi berat badan terhadap kenaikan temperatur tubuh pada pemeriksaan MRI brain

Dilakukan pengukuran berat badan dengan menggunakan timbangan digital, kemudian dilakukan pengukuran temperatur tubuh sebelum pemeriksaan MRI pada ketiak dalam keadaan supine diatas transport table. Pengukuran dilakukan pada ruang tunggu pemeriksaan MRI. Selanjutnya dilakukan pemeriksaan MRI brain dengan menggunakan sequence brain routine selama 19 menit 49 detik. Setelah dilakukan pemeriksaan MRI brain, berpindah ke transport table dengan cara bergeser dan melakukan pengukuran temperatur tubuh kembali pada ketiak dalam keadaan supine pada ruang tunggu pemeriksaan MRI. Kenaikan temperatur tubuh merupakan selisih dari nilai temperatur tubuh setelah dilakukan pemeriksaan dengan nilai temperatur tubuh sebelum dilakukan pemeriksaan MRI brain.

Ada korelasi yang sangat kuat antara variasi berat badan terhadap kenaikan kenaikan temperatur tubuh pada pemeriksaan MRI brain dengan pvalue $<0,05$ dan nilai determinasi $R$ Square $=$ 0,887 yang artinya $88,7 \%$ kenaikan temperatur tubuh dipengaruhi oleh berat badan sedangkan $11,3 \%$ kenaikan temperatur tubuh dipengaruhi oleh faktor lain. Didapat persamaan antara variasi berat badan terhadap kenaikan temperatur tubuh yaitu $\mathrm{y}=2,098-0,024 \mathrm{x}$ dengan $\mathrm{y}$ adalah

temperatur tubuh dan $\mathrm{x}$ adalah berat badan. Artinya, setiap penurunan berat badan dari uji regresi linear pada kolom nilai B. 


\begin{tabular}{ccccc} 
Model & \multicolumn{2}{c}{$\begin{array}{c}\text { Unstandardized } \\
\text { Coefficients }\end{array}$} & $\boldsymbol{t}$ & Sig. \\
& B & Std. Error & & \\
& & & & \\
\hline 1 (Constant) & 0,214 & 0,060 & 3,561 & 0,004 \\
berat & 0,004 & 0,001 & 4,032 & 0,002 \\
\hline
\end{tabular}

sebesar 0,024 $\mathrm{kg}$ akan mempengaruhi kenaikan temperatur tubuh sebesar $2,098^{\circ} \mathrm{C}$.

Secara grafik, pengaruh variasi berat badan terhadap perubahan temperatur tubuh semakin menurun. Kenaikan temperatur tubuh tertinggi sebesar $1,1^{\circ} \mathrm{C}$ pada berat $48,9 \mathrm{~kg}$ dan kenaikan temperatur tubuh terendah sebesar $0,3{ }^{\circ} \mathrm{C}$ pada berat $74,5 \mathrm{~kg}$. Meskipun beberapa tingkat berat terjadi deviasi yaitu pada berat badan 45,6 $\mathrm{kg}$ dan $57,1 \mathrm{~kg}$ secara keseluruhan tingkat kenaikan temperatur tubuh mengalami penurunan.

Pada kelas interval pertama $(45 \mathrm{~kg}$ hingga $54 \mathrm{~kg}$ ) kenaikan temperatur tubuh berkisar $0,9{ }^{\circ} \mathrm{C}$ hingga $1,1{ }^{\circ} \mathrm{C}$, pada kelas interval kedua (55 kg hingga $64 \mathrm{~kg}$ ) kenaikan temperatur tubuh berkisar $0,6^{\circ} \mathrm{C}$ hingga $0,8^{\circ} \mathrm{C}$, dan pada kelas interval ketiga 
(antara $65 \mathrm{~kg}$ hingga $75 \mathrm{~kg}$ ) kenaikan temperatur tubuh berkisar $0,3{ }^{\circ} \mathrm{C}$ hingga 0,5

${ }^{\circ} \mathrm{C}$.

Berdasarkan hasil penelitian, secara keseluruhan setelah dilakukan pemeriksaan MRI terjadi kenaikan temperatur tubuh yang disebabkan oleh paparan RF yang diserap oleh tubuh selama akuisisi belangsung. Menurut Shellock (2000), jumlah panas dalam tubuh selama akuisisi MR tergantung pada jumlah energi RF yang diserap dan disebut nilai SAR.

Sinyal RF yang dipaparkan dari pesawat MRI menyebabkan perpindahan energi ke tubuh dan menyebabkan pemanasan jaringan. Menurut McRobbie (2006), Radiofrekuensi berpotensi memberikan efek seperti deposisi energi, dapat menyebabkan pemanasan pada jaringan.

Berdasarkan hasil tersebut, dapat disimpulkan antara berat badan dan kenaikan temperatur tubuh saling berpengaruh dengan nilai negatif, semakin

berat nilai berat badan maka temperatur tubuh semakin menurun. Hal ini disebabkan karena orang memiliki berat badan berlebih memiliki banyak lemak. Lemak yang berada pada bawah kulit dapat berfungsi menjaga temperatur tubuh pada saat terjadinya perubahan suhu. Menurut Isnaeni (2006), lemak bawah kulit manusia berfungsi untuk menjaga suhu tubuh terhadap perubahan suhu yang terjadi baik panas maupun dingin.

Selain itu, orang dengan berat badan berlebih memiliki permukaan tubuh yang besar, sehingga penyerapan radiofrekuensi dari pesawat MRI tersebar keseluruh tubuh sehingga perubahan temperatur tubuh hanya berpengaruh sedikit. Menurut Bushong (2004), kenaikan temperatur tubuh dipengaruhi paparan medan RF dan waktu paparan selama pemeriksaan MRI. Paparan RF menyesuaikan permukaan obyek yang menentukan nilai serap atau nilai SAR.

Kenaikan temperatur tubuh selama pemeriksaan MRI tidak berbanding lurus dengan kuat paparan medan RF, karena apabila medan magnet kuat, kenaikan temperatur tubuh cenderung sedikit. Menurut Dery (2013), kenaikan temperatur tubuh tidak meningkat secara signifikan berdasarkan BMI yang meningkat. Kenaikan temperatur tubuh bergantung pada 
kekuatan medan magnet, nilai SAR dan lama waktu pemeriksaan.

2. Pengaruh variasi berat badan terhadap nilai SAR pada pemeriksaan MRI brain

$\begin{array}{crr}\text { Dilakukan } & \text { pengukuran } \\ \text { berat } & \text { badan } & \text { dengan }\end{array}$ menggunakan timbangan digital, kemudian memasukkan hasil pengukuran berat badan pada kolom registrasi berat badan. Selanjutnya dilakukan pemeriksaan MRI brain dengan menggunakan sequence brain routine selama 19 menit 49 detik. Setelah dilakukan pemeriksaan MRI brain, melihat nilai SAR pada SAR information yang terdapat pada monitor pesawat MRI.

Ada korelasi yang sedang antara variasi berat badan terhadap nilai SAR pada pemeriksaan MRI brain dengan $p$ value

$<0,05$ dan nilai determinasi $R$ Square $=0,596$ yang artinya $59,6 \%$ nilai $\mathrm{SAR}$ dipengaruhi oleh berat badan sedangkan $40,4 \%$ nilai SAR dipengaruhi oleh faktor lain. Didapat persamaan antara variasi berat badan terhadap nilai SAR yaitu y $=0,214+0,004 \mathrm{x}$ dengan $\mathrm{y}$ adalah nilai SAR dan $\mathrm{x}$ adalah berat badan. Artinya, setiap kenaikan berat badan sebesar $0,004 \mathrm{~kg}$ akan mempengaruhi kenaikan nilai SAR sebesar 0,214 $\mathrm{W} / \mathrm{Kg}$.

Secara grafik, pengaruh variasi berat badan terhadap nilai SAR kepala mengalami kenaikan. Pada berat 45,6 kg hingga 55,2 kg nilai SAR kepala sebesar 0,4 $\mathrm{W} / \mathrm{Kg}$, pada berat $55,7 \mathrm{~kg}$ hingga $74,5 \mathrm{~kg}$ nilai SAR kepala mengalami kenaikan menjadi 0,5 W/Kg. Nilai SAR hanya memperlihatkan angka $0,4 \mathrm{~W} / \mathrm{Kg}$ dan 0,5 W/Kg, hal ini karena SAR kepala terukur hanya dapat menunjukkan angka 1/10.

Berdasarkan hasil tersebut, dapat disimpulkan antara berat badan dan nilai SAR berpengaruh dengan nilai positif, semakin berat nilai berat badan maka nilai SAR akan semakin besar. Hal ini dikarenakan nilai prosentase SAR obyek terukur semakin meningkat bila semakin berat. Pada berat badan 45,6 kg prosentase SAR kepala terukur $12,7 \%$ dan pada berat badan $74,5 \mathrm{~kg}$ prosentase SAR kepala terukur $14,8 \%$. Semakin berat obyek maka semakin besar amplitudo yang diperlukan untuk mendapatkan citra MRI. Menurut Collins (2011), nilai SAR lokal suatu obyek selalu bervariasi sesuai dengan besarnya jaringan. 


\section{Simpulan}

Ada pengaruh variasi berat badan terhadap kenaikan temperatur tubuh pada pemeriksaan MRI brain. Ada korelasi yang sangat kuat dengan $p$ value $<0,05$ dan nilai determinasi $R$ Square $=$ 0,887 yang artinya $88,7 \%$ kenaikan temperatur tubuh dipengaruhi oleh berat badan sedangkan $11,3 \%$ kenaikan temperatur tubuh dipengaruhi oleh faktor lain. Semakin berat nilai berat badan maka semakin rendah peningkatan temperatur tubuh dengan persamaan didapat $\mathrm{y}=2,098-$ 0,024x. Kenaikan temperatur tubuh yang menurun bila nilai berat badan semakin berat disebabkan karena adanya lemak pada jaringan bawah kulit yang dapat menjaga suhu baik panas maupun dingin dan paparan RF menyesuaikan permukaan obyek yang menentukan nilai SAR.

Ada pengaruh variasi berat badan terhadap nilai SAR pada pemeriksaan MRI brain. Ada korelasi yang sedang dengan koefisien korelasi $r$ $=0,772$ dengan $p$ value $<0,05$ dan nilai determinasi $R$ Square $=0,596$ yang artinya $59,6 \%$ nilai SAR dipengaruhi oleh berat badan sedangkan 40,4\% nilai SAR dipengaruhi oleh faktor lain. Semakin berat nilai berat badan maka semakin tinggi nilai SAR dengan persamaan didapat $\mathrm{y}=0,214+0,004 \mathrm{x}$. Nilai SAR yang meningkat disebabkan karena amplitudo pulsa RF menyesuaikan ketebalan organ yang diperiksa.

\section{Daftar Pustaka}

Baker, Kenneth B., Tkach, Jean A, dkk. 2004. Evaluation of Specific Absorption Rate as a Dosimeter of MRI-Related Implant Heating. Cleveland Cliic Foundation, Cleveland, Ohio.

Bushong, Stewart C. 2004. MRI Physical and Biological Principles $3^{\text {rd }}$ ed. CV Mosby Company, USA.

Collins, Christopher M dan Zhangwei Wang. 2011. Calculation of Radiofrequency Electromagnetic Fields and Their Effects in MRI of Human Subjects. Department of Radiology, The Pennsylvania State University.
Depkes. 2002. Petunjuk Teknis Pemantauan Status Gizi Orang Dewasa dengan Indeks Massa Tubuh (IMT). Jakarta.

Dery, Theresa Bebaaku, Joseph Kwabena Amoako, Emmanuel Ofori Darko, Augustine Kwame Kyere, dan Mary Boadu. 2013. Temperature Changes in the 
Brain of Patients Undergoing MRI Examination. Radiological and Medical Sciences and Research Institute, Ghana.

Eknoyan, Garabed. 2008. The Average Man and Indices of Obesity. Oxford University.

Hancock, James. 2010. MRI Study Guide. Australian Institute of Radiography, Australia.

Hashemi, Bradley dan Lisanti. 2010. MRI the Basics. Williams \& Wilkin, Philadelphia, USA.

Homann, Hanno. 2011. SAR Prediction and SAR Management for Parallel Transmit MRI. Institute of Bimedical Engineering Karlsruhe Institute of Technology.

Isnaeni, Wiwi. 2006. Fisiologi Manusia. PT. Rineka Cipta, Bandung.

Kaila, M.M, dan Rakhi Kaila. 2013. Molecular Imaging of the Brain. Springer, New York.

Kaut Roth, Carolyn. 2002. MRI : Imaging Procedures, Patient Care and Safety. Spriner Publising, Verlag, USA.

Kaut Roth, Carolyn. 2002. MRI : Basic Physics, Instrumentation, and Quality Control. Blackwell Science, Carlton, Victoria.

Kim, Myeong Seong. 2016. Investigation of Factors Affecting Body Temperature Changes During Routine Clinical Head Magnetic Resonance Imaging. Korean National Cancer Center, Korea.

Kozier, Barbara, dkk. 2010. Fundamental Keperawatan : Konsep, Proses, dan Praktik. Jakarta : EGC.

Marincas, Cristinel, Marius Mada,
Horatiu Rotaru, Adrian Carpenter, dan Radu Ciupa. 2013. The Termal Effect of Radio Frequency Waves near Dental Implants during MRI Examination at $3 \mathrm{~T}$. European Social Fund Sectorial Operational Program Human Resources, UK.

McRobbie. D, Moore. A, Graves. M dan Prince.

M. 2003. MRI From Picture to Proton $2^{\text {nd }}$ ed. Cambrige University Press, UK, Cambridge.

McRobbie, D. W. 2006. Functional MRI : An Introduction to Methods. Oxford University Press Inc, New York.

Pudjiadi, Antonius dkk. 2010. Pedoman Pelayanan Medis Ikatan Dokter Anak Indonesia Jilid I. Pengurus Pusat Ikatan Dokter Anak Indonesia, Jakarta.

Rasad, Sjahriar. 2006. Radiologi Diagnostik $2^{\text {nd }}$ ed. Badan Penerbit FKUI, Jakarta.

Shellock, Frank G. 2000. Radiofrequency Energy-Induced Heating During MR 
Procedures : A Review. University of Southern Los Angeles, California.

Suhandi, Iwan. 2007. Biologi. Widya Gamma, Jakarta.

Suripto. 2010. Fisiologi Manusia. Penerbit ITB, Bandung.

Wang, Zhangwei dan Christopher M. Collins. 2010. Effect of RF Pulse Sequence on Temperature Elevation for a Given TimeAverage SAR. Department of Radiology and Bioengineering, The Pennsylvania State University, Hershey.

Westbrook, Catherine. 2014. Handbook of MRI Technique $3^{\text {rd }}$ ed. Wiley-Backwell, UK, Cambridge.

Westbrook, Chaterine, Carolyn Kaut Roth, dan John Talbot. 2011. MRI in Practice $4^{\text {th }}$ ed. Wiley-Blackwell Sciene Ltd, United Kingdom.

Woodward, Peggy. 2001. MRI for Technologist, $2^{\text {nd }}$ Edition. McGraw-Hill Medical Publishing Division, Sydney. 